\title{
Efficacy and Safety of Inhaled Cortico- steroids in Patients With COPD: A Systematic Review and Meta-Analysis of Health Outcomes
}

\author{
Gerald Gartlebner, $M D, M P H^{1}$ \\ Richard A. Hansen, PbD, RPb ${ }^{2}$ \\ Shannon S. Carson, $M D^{3}$ \\ Katbleen N. Lobr, PbD ${ }^{4}$ \\ ${ }^{\prime}$ Cecil G. Sheps Center for Health Services \\ Research, University of North Carolina at \\ Chapel Hill, Chapel Hill, NC \\ ${ }^{2}$ Division of Pharmaceutical Policy and \\ Evaluative Sciences, School of Pharmacy, \\ University of North Carolina at Chapel Hill, \\ Chapel Hill, NC
}

${ }^{3}$ Division of Pulmonary and Critical Care Medicine, School of Medicine, University of North Carolina at Chapel Hill, Chapel Hill, NC

${ }^{4}$ Department of Health Policy \& Administration, School of Public Health, University of North Carolina at Chapel Hill, Chapel Hill, NC

\begin{abstract}
PURPOSE We wanted to review systematically the efficacy, effectiveness, and safety of inhaled corticosteroids with respect to health outcomes in patients with chronic obstructive pulmonary disease (COPD).

METHODS We searched MEDLINE, EMBASE, The Cochrane Library, and the International Pharmaceutical Abstracts to identify relevant articles. We limited evidence to double-blinded randomized controlled trials (RCTs) for efficacy, but we also reviewed observational evidence for safety. Outcomes of interest were overall mortality, exacerbations, quality of life, functional capacity, and respiratory tract symptoms. When possible, we pooled data to estimate summary effects for each outcome.

RESULTS Thirteen double-blinded RCTs determined the efficacy of an inhaled corticosteroid compared with placebo; 11 additional studies assessed the safety of inhaled corticosteroid treatment in patients with asthma or COPD. Overall, COPD patients treated with inhaled corticosteroids experienced significantly fewer exacerbations than patients taking placebo (relative risk $[R R]=0.67 ; 95 \% \mathrm{Cl}$, $0.59-0.77$ ). No significant difference could be detected for overall mortality (RR $=0.81 ; 95 \% \mathrm{Cl}, 0.60-1.08)$. Evidence on quality of life, functional capacity, and respiratory tract symptoms is mixed. Adverse events were generally tolerable; pooled discontinuation rates did not differ significantly between inhaled corticosteroid and placebo treatment groups ( $R R=0.92 ; 95 \% \mathrm{Cl}, 0.74-1.14)$. Observational evidence, however, indicates a dose-related risk of cataract and open-angle glaucoma. Severe adverse events, such as osteoporotic fractures, are rare; the clinical importance of the additional risk is questionable.
\end{abstract}

CONCLUSIONS Overall, the risk-benefit ratio appears to favor inhaled corticosteroid treatment in patients with moderate to severe COPD. Existing evidence does not indicate a treatment benefit for patients with mild COPD.

Ann Fam Med 2006;4:253-262. DOI: 10.1370/afm.517.

\section{INTRODUCTION}

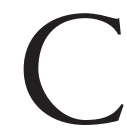
hronic obstructive pulmonary disease (COPD) is among the leading causes of morbidity and mortality worldwide. ${ }^{1}$ In 2000 COPD

Conflicts of interest: none reported

\section{CORRESPONDING AUTHOR}

Gerald Gartlehner, MD, MPH

Cecil G. Sheps Center for

Health Services Research

University of North Carolina at Chapel Hill

725 Airport Road

Chapel Hill, NC 27599

gartlehner@schsr.unc.edu lion emergency department visits, 6.3 million hospitalizations, and 116,513 deaths in the United States. ${ }^{2}$ The World Health Organization estimates that by the year 2020, COPD will be the third-leading cause of death and the fifth-leading cause of disability worldwide. ${ }^{1}$

COPD is characterized by a progressive, irreversible limitation of airflow associated with an abnormal inflammatory response to noxious particles or gases. It is caused primarily by smoking. ${ }^{3,4}$ 
The beneficial effect of inhaled corticosteroid treatment for COPD remains controversial, ${ }^{3,5}$ in part because only smoking cessation is reliably shown to slow the rate of decline in lung function. ${ }^{4}$ Although the Food and Drug Administration (FDA) has not approved inhaled corticosteroids as monotherapy for the treatment of COPD, they are frequently prescribed to reduce or alleviate symptoms, increase exercise capacity, reduce the number and severity of exacerbations, and improve health status. The Global Initiative for Chronic Obstructive Lung Disease recommends inhaled corticosteroid treatment for patients with COPD who have a documented spirometric response to inhaled corticosteroids and for patients with moderate to severe COPD (forced expiratory volume in 1 second $\left[\mathrm{FEV}_{1}\right]<50 \%$ predicted) who have repeated exacerbations that require treatment with antibiotics or oral corticosteroids. ${ }^{6}$ Inhaled corticosteroid treatment is, however, associated with rare but potentially serious adverse events, such as osteoporosis, glaucoma, and cataract, that are difficult to identify in efficacy studies. ${ }^{7}$

Six inhaled corticosteroids are available in the United States: beclomethasone dipropionate (beclomethasone), budesonide, flunisolide, fluticasone propionate (fluticasone), mometasone furoate (mometasone) and triamcinolone acetonide (triamcinolone). Table 1 summarizes their generic names, trade names, manufacturers, dosage form with corresponding devices, strengths, and labeled uses.

Most published studies and systematic reviews ${ }^{8-10}$

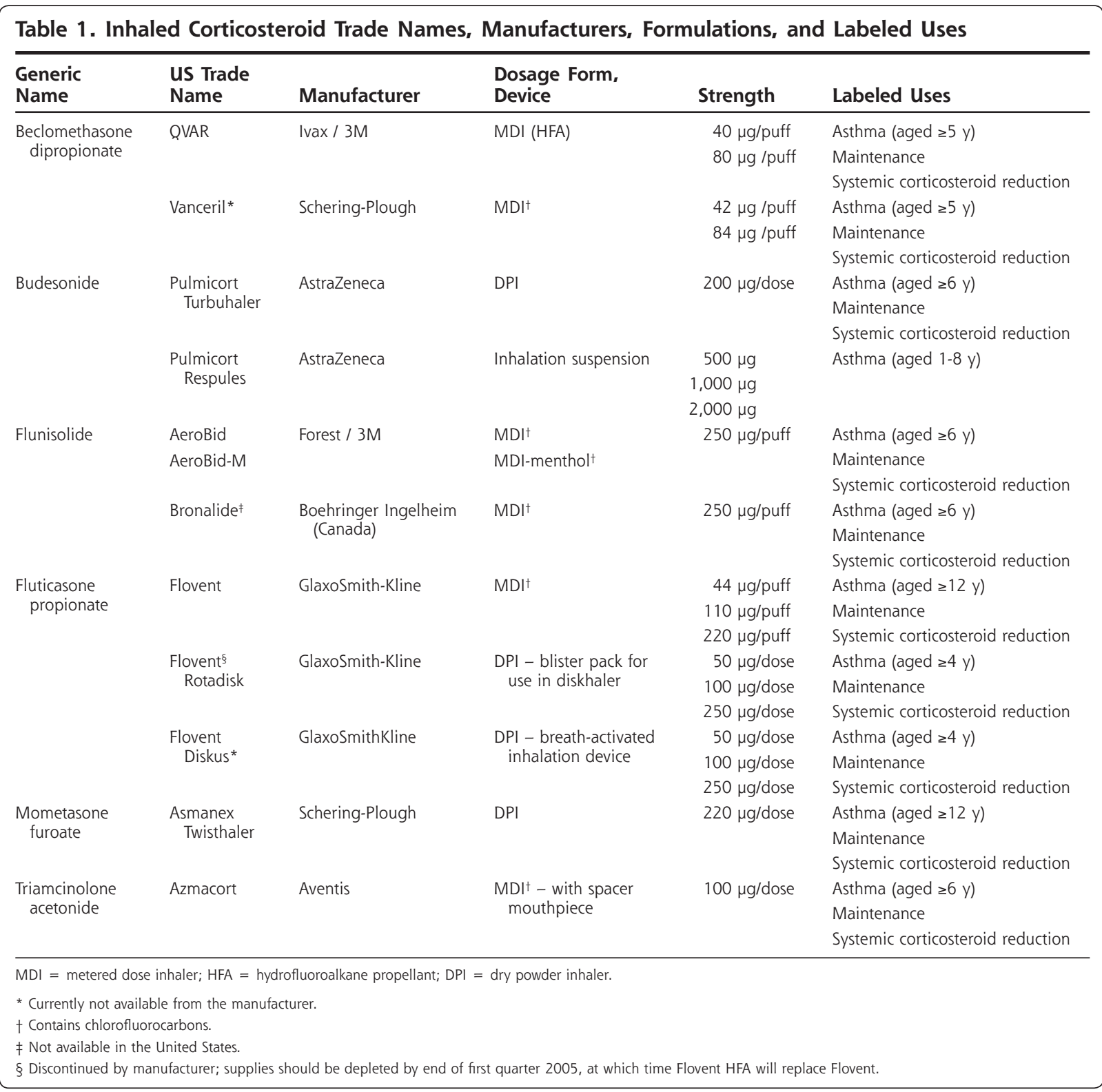


have evaluated the effect of inhaled corticosteroid treatment on $\mathrm{FEV}_{1}$ decline. The rate of $\mathrm{FEV}_{1}$ descent, however, is an imperfect surrogate outcome for clinically important health outcomes, such as health-related quality of life, functional capacity, and exacerbations. ${ }^{11}$ Only one meta-analysis focused primarily on health outcomes ${ }^{12}$; none of these systematic reviews took observational evidence for adverse events into consideration. Limiting adverse events assessment to randomized controlled trials (RCTs) risks missing rare but potentially severe adverse events, such as osteoporotic fractures, glaucoma, or cataract, which RCTs cannot reliably assess because of limitations of sample sizes and study durations.

The objective of this review is to determine the risk-benefit ratio of inhaled corticosteroid treatment for COPD by systematically reviewing the evidence on the efficacy, effectiveness, and safety of inhaled corticosteroid treatment in patients with COPD with respect to health outcomes. Contrary to previous systematic reviews, because our review incorporates observational evidence for adverse events, we provide the first comprehensive assessment of the risk-benefit ratio of inhaled corticosteroid treatment for COPD.

\section{METHODS}

This study is part of a larger systematic review of the comparative effectiveness and tolerability of inhaled corticosteroids in patients with asthma or COPD conducted for the Oregon Drug Effectiveness Review Project (DERP). ${ }^{13}$ We limited outcomes of interest a priori to health outcomes to assure clinical applicability of results.

We searched MEDLINE, EMBASE, The Cochrane Library, and the International Pharmaceutical Abstracts to identify relevant articles. We used either medical subject headings (MeSH or $\mathrm{MH}$ ) as search terms when available or key words when appropriate. We combined terms for the selected indication (COPD) and adverse events with 6 specific inhaled corticosteroids (beclomethasone, budesonide, flunisolide, fluticasone, mometasone, and triamcinolone). We limited the electronic searches to "human" and "English language"; we searched sources from 1970 to 2005 (April) to capture literature relevant to the scope of our topic.

Two persons independently reviewed abstracts; if both reviewers agreed that the trial did not meet eligibility criteria, it was excluded. We reviewed the full text of all eligible articles. Double-blind RCTs of at least 6 months' duration and an outpatient study population were eligible for inclusion. Preestablished exclusion criteria concerned study design or duration, patient population, interventions, and outcomes. We excluded open-label studies from the efficacy analy- sis because empirical evidence indicates that lack of blinding frequently leads to measurement bias and an overestimation of effect sizes. ${ }^{14}$ For adverse events we included both experimental and observational studies. For observational studies we included those with large sample sizes (>100 patients) that lasted at least 1 year and reported an included outcome. For adverse events we also included evidence from mixed populations with asthma and/or COPD.

We assessed the internal validity (quality) of trials based on predefined criteria from the US Preventive Services Task Force (ratings: good-fair-poor) ${ }^{15}$ and the National Health Service Centre for Reviews and Dissemination. ${ }^{16}$ External validity (generalizability) was assessed but did not influence quality ratings. We rated trials with a fatal flaw in one or more categories as poor quality and excluded them from the analysis; we rated trials that met all criteria as good quality. The majority of trials received a quality rating of fair. We accepted the definitions of exacerbation as reported in each study because we did not have access to individual patient data. Although definitions of exacerbation varied across studies, most defined it as an episode requiring oral or parenteral corticosteroids, antibiotics, emergency department visits, or hospitalizations because of increased respiratory tract symptoms.

When possible, we pooled data to obtain summary effect estimates for a given outcome, using relative risks to measure effect sizes. We used fixed-effects models for all meta-analysis because the observed heterogeneity was low $\left(<20 \%\right.$, assessed using the $\mathrm{I}^{2}$ statistic). We assessed publication bias using funnel plots and Kendall's tests, although the validity of these methods is limited given the small number of component studies. All analyses were conducted using StatsDirect 2.3.8 (StatsDirect Ltd, Sale, Cheshire, UK).

\section{RESULTS}

Overall we identified 880 citations. Figure 1 illustrates the disposition of citations and articles. Thirteen double-blinded RCTs determined the efficacy of an inhaled corticosteroid compared with placebo in patients with COPD. We excluded 1 study for quality reasons because of a high rate of postrandomization exclusions. ${ }^{17}$ We included 11 additional studies conducted in adult patients with COPD or asthma to assess the risk of adverse events of long-term inhaled corticosteroid use.

Tables 2 and 3 describe included studies. ${ }^{18-40}$ In efficacy studies, patients were generally smokers or former smokers with a clinical diagnosis of COPD. Only the Copenhagen City Lung Study enrolled smokers identified as having mild COPD during a random population survey and subsequent respiratory system screening. ${ }^{23}$ 
Severity of COPD varied from mild to severe across studies; inclusion criteria tended to exclude patients with asthma or good bronchodilator responsiveness. Patients with a history of asthma, allergic disease, or sudden onset of breathlessness were excluded from all studies. Further, $\mathrm{FEV}_{1}$ reversibility after bronchodilator use was frequently assessed before enrollment; cutoff criteria were between $10 \%$ and $15 \%$. Nine trials $(69 \%)$ were funded by pharmaceutical companies and 3 (23\%) were supported primarily by governmental agencies or independent funds; 1 study (7\%) did not report funding source.

\section{Exacerbations}

Two studies did not provide sufficient data on exacerbation rates and could not be included in the metaanalyses. ${ }^{20,21}$ Overall, pooled results of 4,300 patients from the 10 remaining trials showed a $33 \%$ reduction (95\% CI, 23\%-41\%; RR =0.67; 95\% CI, 0.59-0.77) in COPD exacerbation rates over a mean follow-up period of 20.8 months (Figure 2A). Sensitivity analysis showed that this treatment effect derives largely from studies in populations suffering from moderate

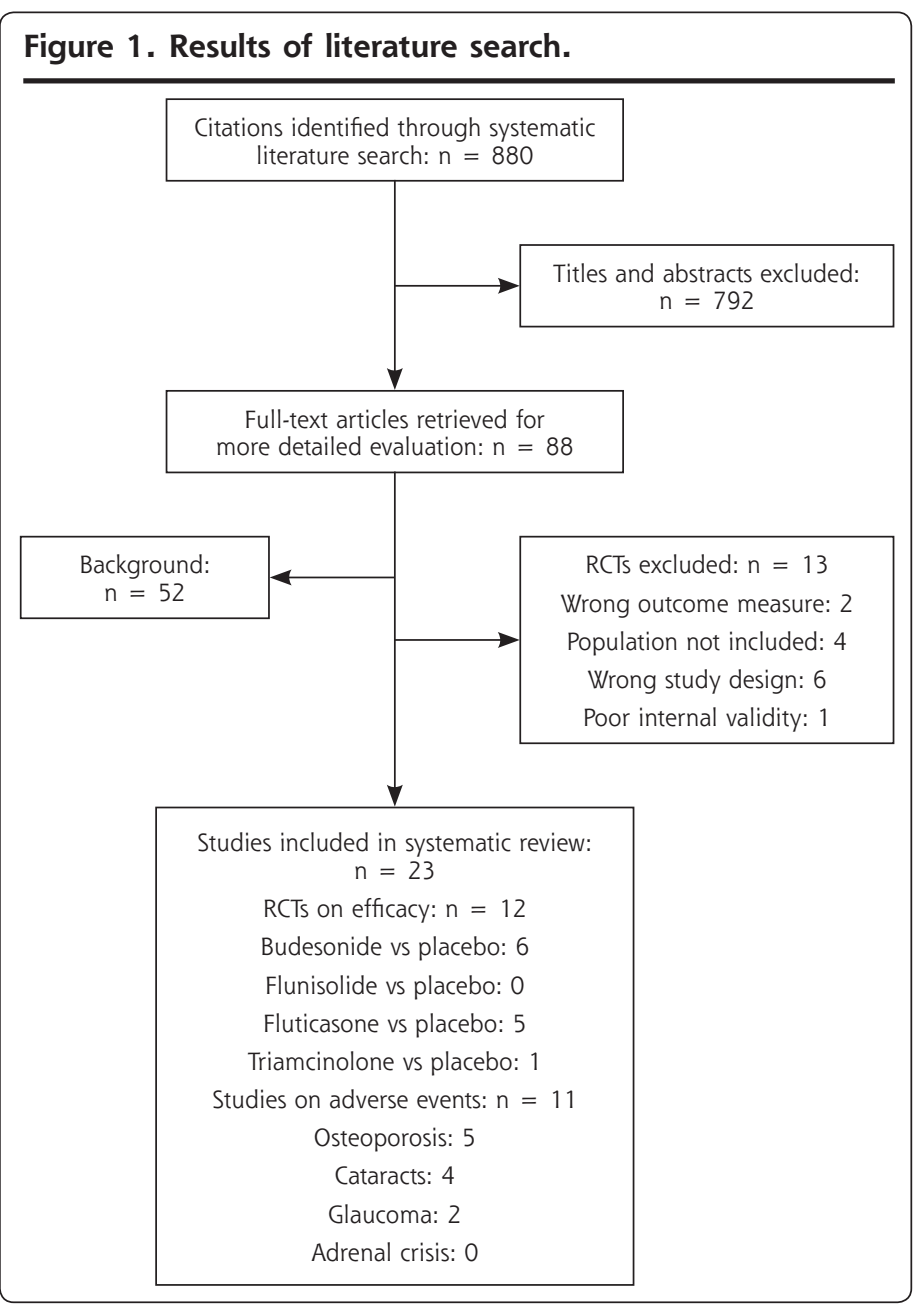

to severe COPD (respectively, $\mathrm{FEV}_{1} \geq 50 \%$ to $<80 \%$ predicted and $\mathrm{FEV}_{1}<50 \%$ predicted according to American Thoracic Association criteria). ${ }^{41}$ Limiting the analysis to the 7 trials with populations with moderate to severe COPD (ie, excluding populations with mild COPD) produces an estimated benefit of inhaled corticosteroid treatment almost identical to the results of the overall meta-analysis ( $\mathrm{RR}=0.66 ; 95 \% \mathrm{CI}, 0.57$ 0.75 ) (Figure 2B). The number needed to treat (NNT) in this population is 12 (95\% CI, 9-18); ie, 12 patients with moderate to severe COPD need to be treated with an inhaled corticosteroid for 17.7 months to avoid 1 exacerbation. For the population with mild COPD $\left(\mathrm{FEV}_{1} \geq 80 \%\right.$ predicted), we pooled results of 3 small studies $(\mathrm{n}=191)$; no benefit of inhaled corticosteroid treatment emerged ( $R R=0.92 ; 95 \% \mathrm{CI}, 0.55-1.53)$. As noted, the sample size of this analysis is small, and point estimates of both subgroup analyses are within each other's confidence intervals. Inferences about differences of treatment effects must be made cautiously.

In sensitivity analyses we compared pooled results of studies of newer inhaled corticosteroids (ie, fluticasone) that have a large degree of first-pass metabolism ${ }^{42,43}$ with those of older inhaled corticosteroids (ie, beclomethasone, budesonide, flunisolide, and triamcinolone). Relative benefits of both groups were almost identical (newer inhaled corticosteroids: RR $=0.69[0.59-0.80]_{;}$older inhaled corticosteroids: $\mathrm{RR}=0.65[95 \% \mathrm{CI}, 0.53-0.79]$ ).

\section{Mortality}

The pooled relative risks $(\mathrm{RR}=0.81 ; 95 \% \mathrm{CI}$, $0.60-1.08$ ) for 4,370 patients resulted in no significant difference in all-cause mortality (Figure $3 \mathrm{~A}$ ). Overall, $2.9 \%$ of patients on placebo and $2.5 \%$ of patients on inhaled corticosteroids died $(P=.27)$ during the mean follow-up period of 22.3 months. Limiting the analysis to studies of moderate to severe COPD (Figure $3 \mathrm{~B})$ yielded almost identical results $(\mathrm{RR}=0.84$; 95\% CI, 0.61-1.15). No differences in mortality were apparent between groups taking newer and older inhaled corticosteroids.

\section{Functional Capacity and Quality of Life} In the few studies that assessed functional capacity or quality of life, outcome measures were too heterogeneous to pool results in a meta-analysis; therefore, we analyzed findings qualitatively.

Five studies examined functional capacity and quality of life in patients with moderate to severe COPD. ${ }^{18,19,22,26,27}$ Two trials 
Table 2. Summary of Included Randomized Controlled Trials on Efficacy of Inhaled Corticosteroids in COPD

\begin{tabular}{|c|c|c|c|c|c|c|}
\hline Author, Year & $\begin{array}{c}\text { Mean Age } \\
\text { (years) }\end{array}$ & No. & Duration & Dosage, Device & $\begin{array}{c}\text { Mean Baseline FEV } \\
\text { (\% of predicted) }\end{array}$ & $\begin{array}{l}\text { Quality } \\
\text { Rating }\end{array}$ \\
\hline \multicolumn{7}{|l|}{ Budesonide vs placebo } \\
\hline Bourbeau et al, ${ }^{18} 1998$ & 66 & 79 & $6 \mathrm{mo}$ & $1,600 \mu \mathrm{g} / \mathrm{d}, \mathrm{DPI}$ & 36.5 & Fair \\
\hline Calverley et al, ${ }^{19} 2003$ & 64 & 513 & $1 \mathrm{y}$ & $800 \mu \mathrm{g} / \mathrm{d}, \mathrm{DPI}$ & 36 & Fair \\
\hline Pauwels et al,20 1999 (EUROSCOP) & 52 & 1,277 & $3 y$ & $800 \mu \mathrm{g} / \mathrm{d}, \mathrm{DPI}$ & 77 & Fair \\
\hline Renkema et al, ${ }^{21} 1996$ & 55 & 40 & $2 y$ & $1,600 \mu \mathrm{g} / \mathrm{d}, \mathrm{MDI}$ & 64 & Fair \\
\hline Szafranski et al, ${ }^{22} 2003$ & 64 & 403 & $1 \mathrm{y}$ & $800 \mu \mathrm{g} / \mathrm{d}, \mathrm{MDI}$ & 36 & Fair \\
\hline Vestbo et al, 231999 & 59 & 290 & $3 y$ & $1,200 \mu \mathrm{g} / \mathrm{d}, \mathrm{DPI}$ & 86 & Fair \\
\hline \multicolumn{7}{|l|}{ Fluticasone vs placebo } \\
\hline Albers et $\mathrm{al}_{,}{ }^{24} 2004$ & 50 & 85 & $2 y$ & $500 \mu \mathrm{g} / \mathrm{d}, \mathrm{MDI}$ & 90 & Good \\
\hline Burge et al, 252000 (ISOLDE) & 64 & 751 & $3 y$ & $1,000 \mu \mathrm{g} / \mathrm{d}, \mathrm{MDI}$ & 50 & Fair \\
\hline Calverley et al, ${ }^{26} 2003$ & 63 & 735 & $1 \mathrm{y}$ & $1,000 \mu \mathrm{g} / \mathrm{d}, \mathrm{DPI}$ & 45 & Good \\
\hline Paggiaro et al, ${ }^{27} 1998$ & 63 & 281 & $6 \mathrm{mo}$ & $1,000 \mu \mathrm{g} / \mathrm{d}, \mathrm{MDI}$ & 57 & Good \\
\hline van Grunsven et al, 28003 & 47 & 48 & $2 y$ & $500 \mu \mathrm{g} / \mathrm{d}, \mathrm{DPI}$ & 96 & Fair \\
\hline \multicolumn{7}{|l|}{ Triamcinolone vs placebo } \\
\hline Lung Health Study ${ }^{29}$ & 56 & 1,116 & $3 \mathrm{y}, 4 \mathrm{mo}$ & $1,200 \mu \mathrm{g} / \mathrm{d}, \mathrm{MDI}$ & 64 & Fair \\
\hline
\end{tabular}

Table 3. Summary of Included Studies on Adverse Events of Inhaled Corticosteroids in COPD

\begin{tabular}{|c|c|c|c|c|c|}
\hline Author, Year & $\mathbf{N}$ & Design & Population & Results & $\begin{array}{l}\text { Quality } \\
\text { Rating }\end{array}$ \\
\hline \multicolumn{6}{|c|}{ Bone density and osteoporotic fractures } \\
\hline Jones et al, ${ }^{30} 2004$ & NA & Systematic review & Asthma and COPD & $\begin{array}{l}\text { No difference in BMD and osteoporotic } \\
\text { fractures between ICS and placebo }\end{array}$ & Fair \\
\hline Hubbard et al, ${ }^{31} 2002$ & 16,341 & Case-control & Asthma and COPD & $\begin{array}{l}\text { Nonspecific ICS use associated with } \\
\text { a small increase in the risk of hip } \\
\text { fracture }\end{array}$ & Good \\
\hline Israel et al, ${ }^{32} 2001$ & 109 & Prospective cohort & Women (aged 18-45 y) & $\begin{array}{l}\text { Triamcinolone associated with dose- } \\
\text { related decline in BMD (total hip and } \\
\text { trochanter) of } 0.00044 \mathrm{~g} / \mathrm{cm}^{2} \text { per } \\
\text { puff/year }\end{array}$ & Fair \\
\hline Johnell et al, ${ }^{33} 2002$ & 1,277 & $\mathrm{RCT}$ & COPD & $\begin{array}{l}\text { No difference in bone density between } \\
\text { BUD and placebo over } 3 \text { y; no differ- } \\
\text { ence in bone density or vertebral frac- } \\
\text { tures in subgroup of } 912 \text { smokers }\end{array}$ & Fair \\
\hline Lee $\&$ Weiss, ${ }^{34} 2004$ & 8,525 & Nested case-control & COPD & $\begin{array}{l}\text { Nonspecific ICS use associated with } \\
\text { increased risk of fractures at high doses }\end{array}$ & Good \\
\hline \multicolumn{6}{|c|}{ Posterior subcapsular cataracts } \\
\hline Cumming et al, ${ }^{35} 1997$ & 3,654 & Cross-sectional & $\begin{array}{l}\text { Adults; asthma and } \\
\text { COPD; aged 49-97 y }\end{array}$ & $\begin{array}{l}\text { Increased risk of nuclear and PSC } \\
\text { among ICS users }\end{array}$ & $\mathrm{N} / \mathrm{A}$ \\
\hline Garbe et al, ${ }^{36} 1998$ & 25,545 & Case-control & $\begin{array}{l}\text { RAMQ; asthma and } \\
\text { COPD; aged } \geq 70 \mathrm{y}\end{array}$ & $\begin{array}{l}\text { Increased risk of cataract extraction } \\
\text { for ICS users only at high dose and } \\
\text { duration }\end{array}$ & Good \\
\hline Jick et al, ${ }^{37} 2001$ & $\begin{array}{l}201,816 \\
(3,581)\end{array}$ & Cohort + case-control & $\begin{array}{l}\text { GPRD; asthma and } \\
\text { COPD; aged 3-90 y }\end{array}$ & $\begin{array}{l}\text { Dose-, duration-, and age-related } \\
\text { increased risk of cataracts among ICS } \\
\text { users; no increase in risk for age }<40\end{array}$ & Good \\
\hline Smeeth et al, ${ }^{38} 2003$ & 30,958 & Case-control & $\begin{array}{l}\text { GPRD; asthma and } \\
\text { COPD; aged } \geq 40 \text { y }\end{array}$ & $\begin{array}{l}\text { Dose- and duration-related increased } \\
\text { risk of cataracts among ICS users }\end{array}$ & Good \\
\hline \multicolumn{6}{|c|}{ Ocular hypertension and open-angle glaucoma } \\
\hline Garbe et al, ${ }^{39} 1997$ & 48,118 & Case-control & RAMQ aged $\geq 66 y$ & $\begin{array}{l}\geq 3 \text { mo high-dose ICS associated with } \\
\text { increased risk of open-angle glau- } \\
\text { coma and ocular hypertension }\end{array}$ & Fair \\
\hline Mitchell et al, ${ }^{40} 1999$ & 3,654 & Cross-sectional & $\begin{array}{l}\text { Adults; asthma and } \\
\text { COPD; aged 49-97 y }\end{array}$ & $\begin{array}{l}\text { Dose-related increased risk of elevated } \\
\text { IOP and open-angle glaucoma for ICS } \\
\text { users with glaucoma family history }\end{array}$ & $N / A$ \\
\hline
\end{tabular}


administered a 6 -minute walking test after 6 months of inhaled corticosteroid treatment. In one, 6-minute walking distance was significantly greater for patients on fluticasone $1,000 \mathrm{mg} / \mathrm{d}$ than for patients on placebo $\left(+27 \mathrm{~m}\right.$ vs $\left.+9 \mathrm{~m}_{i} P=.032\right) .{ }^{27} \mathrm{~A}$ smaller Canadian study

Figure 2. Relative risk meta-analysis of effects of inhaled corticosteroids on exacerbations.

\section{A. ICS vs placebo in mild to severe COPD (fixed effects)}

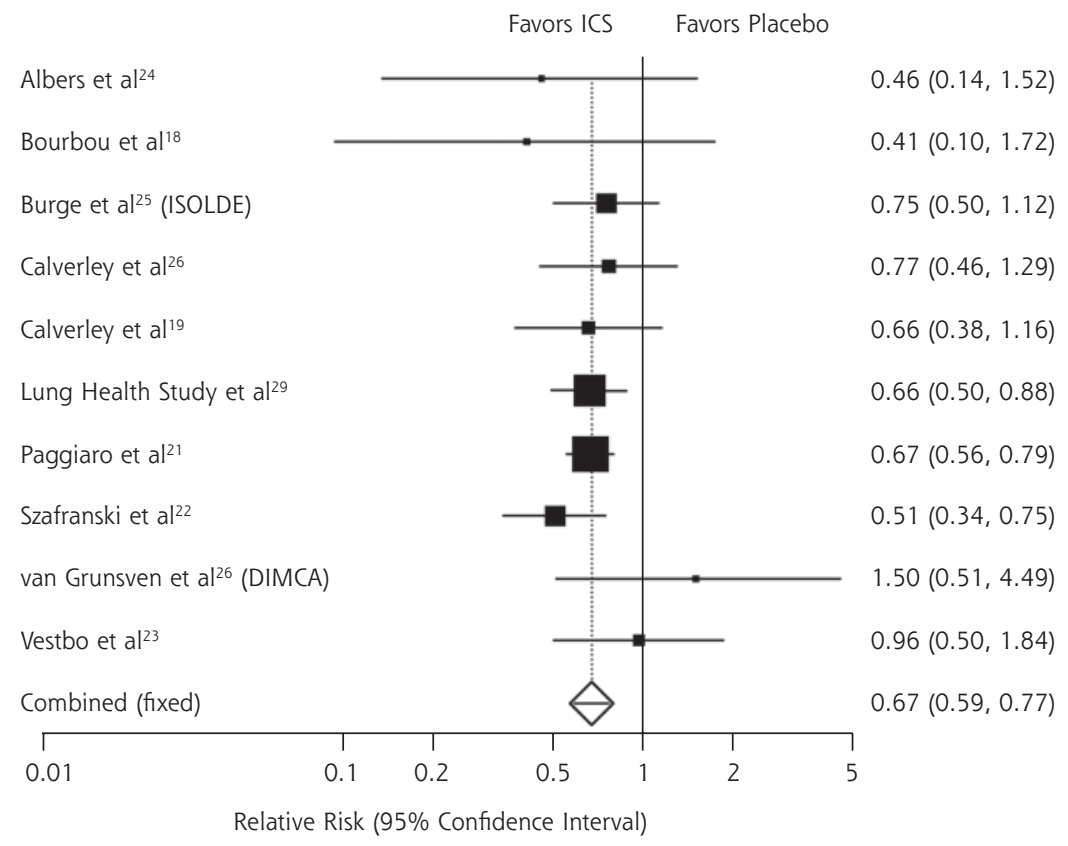

B. ICS vs placebo in moderate to severe COPD (fixed effects)

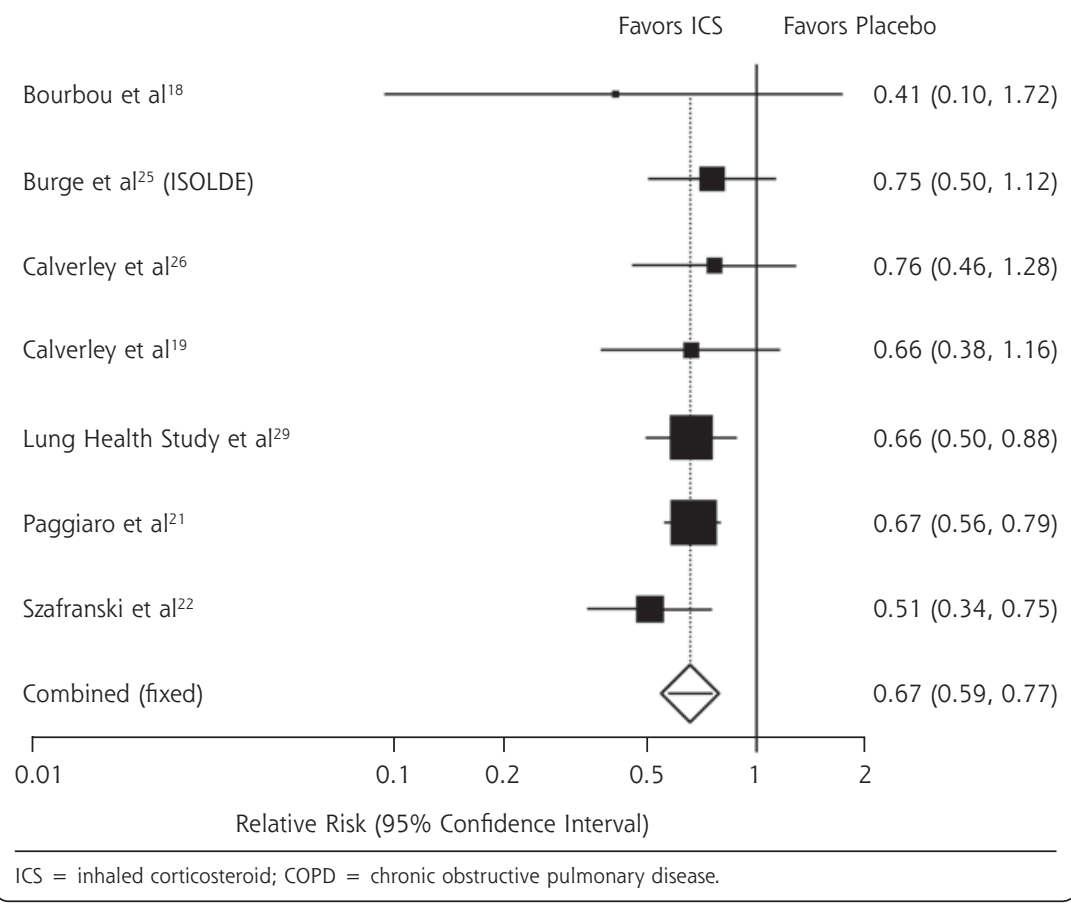

did not detect any significant difference in walking distances for patients when comparing budesonide 1,600 $\mathrm{mg} / \mathrm{d}$ with placebo $\left(-15 \mathrm{~m}\right.$ vs $\left.+13 \mathrm{~m}_{i} \mathrm{P}=\mathrm{NR}\right){ }^{18}$ This trial also reported no significant differences in scores on the Chronic Respiratory Disease Questionnaire.
Three studies of patients with severe COPD reported greater improvements in St. George's Respiratory Questionnaire for patients on budesonide $800 \mathrm{mg} / \mathrm{d}$ or fluticasone $1,000 \mu \mathrm{g} / \mathrm{d}$ than for patients on placebo ${ }^{19,22,26}$; however, the clinical importance of the reported differences (range: -0.8 to -3.0$)$ is uncertain.

Two Dutch studies originating from the DIMCA (Detection, Intervention, and Monitoring of COPD and Asthma) program, which recruited patients with mild COPD through population screening, did not find any differences in functional capacity for patients on fluticasone 500 $\mathrm{mg} / \mathrm{d}$ and those on placebo after 2 years of treatment. ${ }^{24,28}$

\section{Respiratory Symptoms}

Most studies assessed respiratory system symptom scores, but the reported data were mixed and insufficient for meta-analysis. Four studies reported no significant differences in respiratory system symptoms when comparing inhaled corticosteroid with placebo. ${ }^{18,23,26,28}$ Three studies detected no overall differences in respiratory systems symptoms but did detect significant improvements in subscales, such as daily cough scores, sputum volume, ${ }^{27}$ night time awakenings, ${ }_{1}^{19}$ and dyspnea. ${ }^{29}$ In comparisons with placebo, 1 trial reported significantly lower symptom scores in patients during 2 years' treatment with budesonide $1,600 \mathrm{mg} / \mathrm{d}^{21}$ and another during 3 years' treatment with fluticasone $1,000 \mathrm{mg} / \mathrm{d} .{ }^{25}$

\section{Adverse Events}

Efficacy trials commonly reported rhinitis, oral candidiasis, sore 


\section{Figure 3. Relative risk meta-analysis of effects of inhaled corticosteroids: all-cause mortality.}

\section{A. ICS vs placebo in mild to severe COPD (fixed effects)}

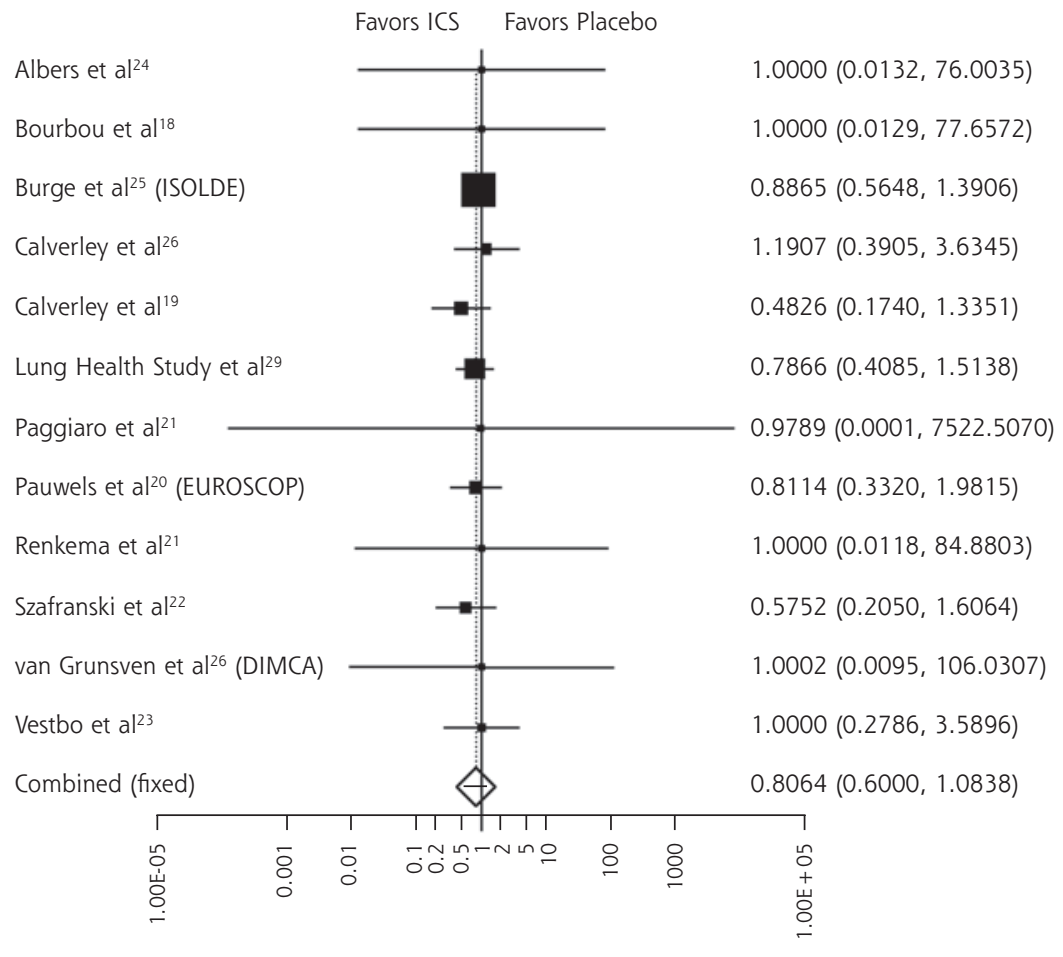

Relative Risk (95\% Confidence Interval)

B. ICS vs placebo in moderate to severe COPD (fixed effects)

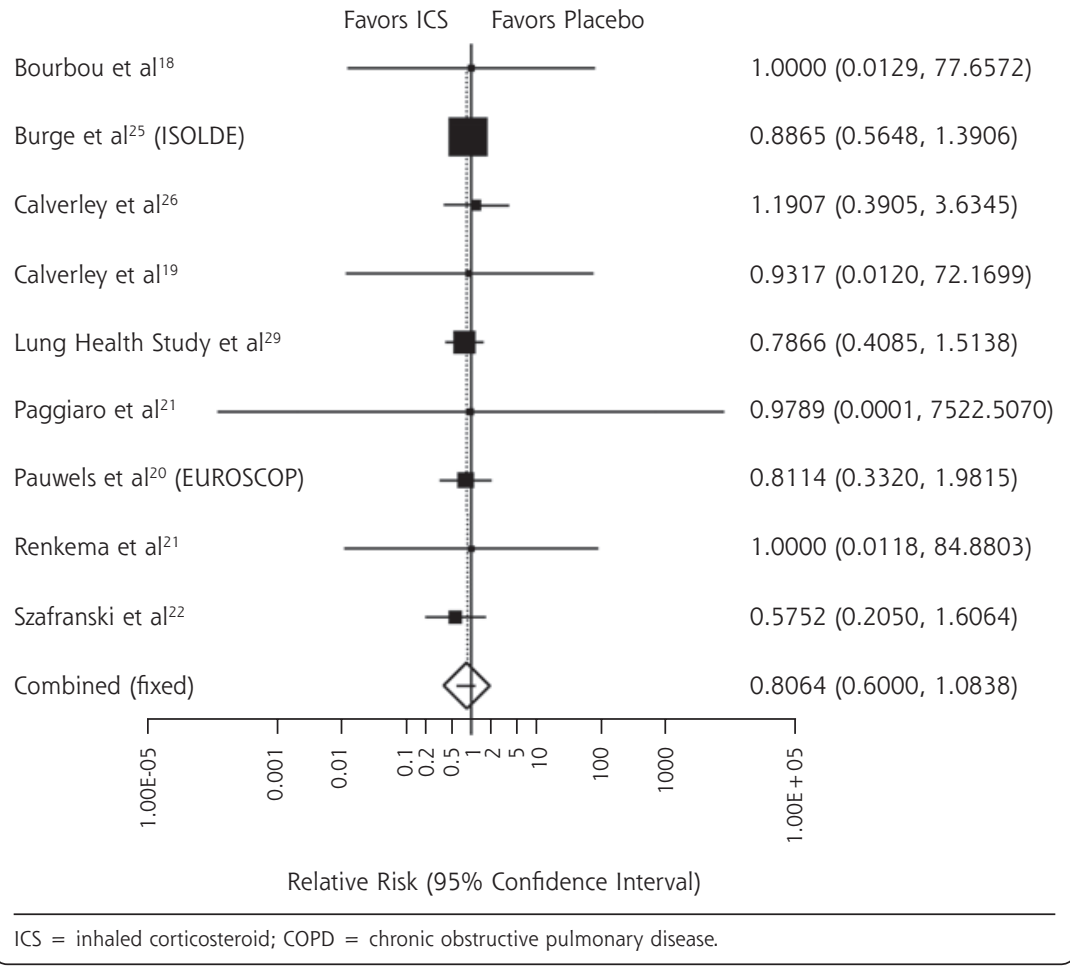

throat, bruising, hoarseness, headache, cough, bronchitis, and upper respiratory infection. In most studies, incidence was below $10 \%$. Pooled discontinuation rates because of adverse events did not differ significantly between inhaled corticosteroids and placebo $(\mathrm{RR}=0.92 ; 95 \% \mathrm{CI}, 0.74$ 1.14). Most studies combined patient-reported adverse events with a regular clinical examination by an investigator. Short study durations and small sample sizes limited the validity of adverse events assessment in many trials. Many studies excluded eligible participants that did not tolerate treatment during the run-in period, limiting the generalizability of adverse events assessment.

To take the limitations of RCTs into consideration and to assess rare but potentially serious adverse events, we also reviewed observational studies (Table 3 ). Specifically, we were interested in osteoporosis, posterior subcapsular cataracts, ocular hypertension, and open-angle glaucoma.

\section{Bone Density and Osteoporotic} Fractures

Overall, the evidence of an association between inhaled corticosteroid products and osteoporosis is mixed. A meta-analysis of randomized trials found no evidence of increased risk of loss of bone mineral density (BMD) or fractures, ${ }^{30}$ which is consistent with findings from an RCT not included in that meta-analysis. ${ }^{20,33}$

The strongest observational evidence comes from 2 case-control studies that measured fractures ${ }^{31,34}$; both reported a slight increase in the risk of fracture for inhaled corticosteroid-treated patients. In 1 study, only current high-dose users $(\geq 700 \mu \mathrm{g} / \mathrm{d})$ had an increased risk of nonvertebral fractures $(\mathrm{OR}=1.68 ; 95 \% \mathrm{CI}$, 1.10-2.57). ${ }^{34}$ In the other, the 
risk of hip fracture was significantly higher in patients using an inhaled corticosteroid $(\mathrm{OR}=1.19 ; 95 \% \mathrm{CI}$, 1.10-1.28). Additionally, evidence of an inhaled corticosteroid-associated reduction in BMD comes from a prospective cohort study in 109 premenopausal women $^{32}$ : an estimated bone loss of $0.00044 \mathrm{~g} / \mathrm{cm}^{2}$ per puff per year of treatment. We view BMD as an intermediate outcome measure of osteoporosis; although a causal relationship exists between loss of BMD and risk of fractures from osteoporosis, the clinical importance of modest changes in BMD is often questionable.

\section{Cataracts}

The association between systemic corticosteroids and cataracts, especially at high doses administered for extended periods, is well documented in both children ${ }^{44}$ and adults. ${ }^{45}$ Systemic corticosteroid-induced cataracts typically are located on the posterior side of the lens and are referred to as posterior subcapsular cataracts.

Four observational studies evaluated the risk of adult patients developing cataracts, comparing nonspecific inhaled corticosteroid use with no inhaled corticosteroid use. ${ }^{35-38}$

A British case-control study of 15,479 patients with cataracts detected a modest but significant increase in risk for the overall use of inhaled corticosteroids (adjusted OR $=1.10 ; 95 \% \mathrm{CI}, 1.00-1.20) .{ }^{38} \mathrm{~A}$ subgroup analysis of COPD patients, however, showed no significant increase in risk (adjusted $\mathrm{OR}=1.03 ; 95 \%$ $\mathrm{CI}, 0.94-1.13)$. These results suggest a cumulative risk of inhaled corticosteroid use for the development of cataracts, because patients with asthma are generally exposed to inhaled corticosteroids for longer periods of their lives than are patients with COPD.

These findings are consistent with other observational evidence in patients with asthma or COPD. A retrospective cohort study with a nested case-control study, ${ }_{1}{ }^{37}$ a case-control study, ${ }^{36}$ and a cross-sectional study ${ }^{35}$ reported increased dose- and duration-dependent risks of inhaled corticosteroids use for posterior cataract. These studies do not report on COPD patients alone.

\section{Ocular Hypertension and Open-Angle Glaucoma} In 1 case-control study of 48,118 Canadians aged 66 years and older ${ }^{39}$ and 1 cross-sectional population-based eye study of 3,654 Australians aged 49 to 97 years, ${ }^{40}$ the risk of increased intraocular pressure or open-angle glaucoma was compared in patients using inhaled corticosteroids and patients not using inhaled corticosteroids. Both studies adjusted for age, sex, oral steroid use, history of diabetes, and history of hypertension but did not stratify by COPD patients. Both reported a doserelated increase in the risk of open-angle glaucoma for inhaled corticosteroid-treated patients compared with patients who had not used an inhaled corticosteroid. ${ }^{39,40}$ The case-control study observed this relationship only among current users of high doses of inhaled corticosteroids prescribed regularly for 3 or more months (adjusted OR $=1.44 ; 95 \% \mathrm{CI}, 1.01-2.06)^{39} ;$ patients on low to medium doses did not have an increased risk (adjusted $\mathrm{OR}=0.95 ; 95 \% \mathrm{CI}, 0.77-1.19)$. In the crosssectional study the association between ever using inhaled corticosteroids and elevated intraocular pressure or glaucoma occurred only in patients with a family history of glaucoma $(\mathrm{OR}=2.8 ; 95 \% \mathrm{CI}, 1.2-6.8){ }^{40}$

\section{DISCUSSION}

Our meta-analysis suggests that COPD patients treated with inhaled corticosteroids experience significantly fewer exacerbations than patients on placebo. The relative risk reduction is $33 \%$; the NNT to prevent 1 exacerbation during 20.8 months is 12 . This treatment effect is apparently stronger in patients with moderate to severe COPD. Pooled estimates for patients with mild COPD did not suggest a reduction of exacerbations. Sample sizes are too small, however, for clear inferences about the efficacy of inhaled corticosteroid treatment in patients with mild COPD.

We could not detect a significant benefit of inhaled corticosteroid treatment with respect to overall mortality, which in part may be attributable to short study durations (maximum 3 years) relative to the long natural course of disease and to the lack of power to detect such an outcome. We chose overall mortality as an outcome measure rather than COPD mortality, as it does not depend on a subjective judgment by outcome assessors and is therefore less prone to bias. The body of evidence concerning quality of life and functional capacity is mixed and yields no basis for clear conclusions. Empirical evidence suggests, however, that patient quality of life is related to the frequency of COPD exacerbation. ${ }^{46,47}$ Thus, fewer exacerbations resulting from inhaled corticosteroid treatment can provide indirect evidence for improved quality of life. In addition, inhaled corticosteroid treatment will spare some patients from dealing with systemic corticosteroids.

Efficacy data indicate that adverse events are usually mild and do not lead to significantly higher discontinuation rates for inhaled corticosteroid-treated than for placebo-treated patients. Osteoporotic fractures are rare; the clinical importance of the additional risk is questionable. Evidence from large observational studies consistently indicates a modest risk of cataracts and open-angle glaucoma ${ }_{i}$ it is attributable largely to high dosage and long duration of inhaled corticosteroid use.

Our findings are partly consistent with earlier meta-analyses that assessed exacerbation rates., ${ }^{9}{ }^{12}$ Van 
Grunsven et $\mathrm{al}^{9}$ reported no significant differences in exacerbation rates between the group on inhaled corticosteroids and the group on placebo. Results of a meta-analysis by $\mathrm{Sin}$ et $\mathrm{l}^{12}$ are consistent with our findings.Point estimates from our analyses, however, are more precise because of the greater number of component studies. Furthermore, neither of the 2 previous reviews included observational evidence for adverse events to assess the risk-benefit ratio of inhaled corticosteroid treatment. Results of long-term observational studies with respect to exacerbations and mortality are mixed. ${ }^{48-53}$ The COPE study, a double-blind discontinuation study of fluticasone $(1,000 \mu \mathrm{g} / \mathrm{d})$, reported that patients who discontinued inhaled corticosteroid therapy had a significantly higher recurrence risk of exacerbations than patients who remained on fluticasone treatment. ${ }^{49}$

We note several limitations in this literature and our work. Durations of efficacy studies are usually too short and sample sizes too small to assess reliably the effects on rare long-term outcomes (eg, mortality) and on rare but severe adverse events. Observational studies posed methodological concerns that precluded meta-analysis.

Because we did not have access to individual patient data, we assumed that definitions of exacerbations did not differ substantially across trials. Although this assumption could lead to some imprecision with respect to efficacy, it might also increase external validity because it synthesizes various definitions of exacerbation used in clinical practice. Moreover, we reviewed inhaled corticosteroids as a class, not taking differences in potency, delivery device, systemic exposure, and dosing into consideration. No treatment regimen appeared to be underdosed; however, because we could not conduct quantitative analyses on adverse events, we were unable to assess whether inhaled corticosteroids with low systemic absorption lead to fewer adverse events than inhaled corticosteroids with high systemic absorption. Our pooled efficacy results might underestimate treatment effects for patients with severe COPD who usually receive high-dose treatments. Differential loss to follow-up might also dilute treatment effects. Placebo groups consistently had a higher dropout rate than inhaled corticosteroid groups. The frequency of exacerbations and mortality might therefore be underestimated for placebo treatment.

None of the included studies can be viewed as an effectiveness trial with a high degree of generalizability. The patient populations often were highly selected and included exclusively current or former smokers. Patients with $\mathrm{FEV}_{1}$ reversibility of more than $10 \%$ to $15 \%$ were typically excluded. These factors further limit the generalizability of results for nonsmoking patients with asthma who have chronic air- ways obstruction. Even so, good evidence exists from multiple trials that inhaled corticosteroid treatment is efficacious in patients with asthmatic features. ${ }^{13}$

Finally, we could not include unpublished studies; their absence may lead to an overestimation of treatment effects.

Additional large studies are needed that have the necessary power to address such health outcomes as mortality and quality of life. Results of the ongoing TORCH (Towards a Revolution in COPD Health) survival study may provide answers to some remaining questions. ${ }^{54}$ This 3 -year, multicenter trial is randomizing approximately 6,200 patients with moderate to severe COPD to placebo, fluticasone, fluticasone/salmeterol, or salmeterol; it will end in 2006.

To read or post commentaries in response to this article, see it online at http://www.annfammed.org/cgi/content/full/4/3/253.

Key words: Chronic obstructive pulmonary disease/drug therapy; corticosteroids; health outcomes; systematic review; meta-analysis

Submitted June 9, 2005; submitted, revised, September 27, 2005; accepted October 27, 2005.

Funding support: Funding for this research was provided to the Cecil G. Sheps Center for Health Services Research through a subcontract with the Center for Evidence-Based Policy; Oregon Health \& Science University.

Acknowledgments: We would like to thank Timothy Carey, MD, MPH, who provided insightful comments on various drafts of this paper.

\section{References}

1. Murray CJ, Lopez AD. Alternative projections of mortality and disability by cause 1990-2020: Global Burden of Disease Study. Lancet. 1997;349:1498-1504.

2. National Center for Health Statistics. NCHS data on chronic obstructive pulmonary disorder. Available at: http://www.cdc.gov/nchs/ data/factsheets/copd.pdf. Accessed: 22 September 2005.

3. Fabbri LM, Hurd SS. Global Strategy for the Diagnosis, Management and Prevention of COPD: 2003 update. Eur Respir J. 2003;22:1-2.

4. Anthonisen NR, Connett JE, Murray RP. Smoking and lung function of Lung Health Study participants after 11 years. Am J Respir Crit Care Med. 2002;166:675-679.

5. Pauwels R. Inhaled glucocorticosteroids and chronic obstructive pulmonary disease: how full is the glass? Am J Respir Crit Care Med. 2002;165:1579-1580.

6. Pauwels RA, Buist AS, Calverley PM, Jenkins CR, Hurd SS. Global strategy for the diagnosis, management, and prevention of chronic obstructive pulmonary disease. NHLBI/WHO Global Initiative for Chronic Obstructive Lung Disease (GOLD) Workshop summary. Am J Respir Crit Care Med. 2001;163:1256-1276.

7. McEvoy CE, Niewoehner DE. Adverse effects of corticosteroid therapy for COPD. A critical review. Chest. 1997;111:732-743.

8. Sutherland ER, Allmers H, Ayas NT, Venn AJ, Martin RJ. Inhaled corticosteroids reduce the progression of airflow limitation in chronic obstructive pulmonary disease: a meta-analysis. Thorax. 2003;58:937-941.

9. van Grunsven PM, van Schayck CP, Derenne JP, et al. Long term effects of inhaled corticosteroids in chronic obstructive pulmonary disease: a meta-analysis. Thorax. 1999;54:7-14.

10. Highland KB. Inhaled corticosteroids in chronic obstructive pulmonary disease: is there a long-term benefit? Curr Opin Pulm Med. 2004; 10:113-119. 
11. Spencer S, Calverley PM, Sherwood Burge $P$, Jones PW. Health status deterioration in patients with chronic obstructive pulmonary disease. Am J Respir Crit Care Med. 2001;163:122-128.

12. Sin DD, McAlister FA, Man SF, Anthonisen NR. Contemporary management of chronic obstructive pulmonary disease: scientific review. JAMA. 2003;290:2301-2312.

13. Drug class review on inhaled corticosteroids. 2005. Available at: http://www.ohsu.edu/drugeffectiveness/reports/documents/ICS\%20 Final\%20Report\%20January\%2020052.pdf. Accessed: 22 September 2005.

14. Kunz R, Oxman AD. The unpredictability paradox: review of empirical comparisons of randomised and non-randomised clinical trials. BMJ. 1998;317:1185-1190.

15. Harris RP, Helfand M, Woolf $\mathrm{SH}$, et al. Current methods of the US Preventive Services Task Force: a review of the process. Am J Prev Med. 2001;20:21-35

16. Undertaking Systematic Reviews of Research on Effectiveness: CRD's Guidance for Those Carrying Out or Commissioning Reviews. York, UK: Centre for Reviews and Dissemination, University of York; 2001.

17. Weir DC, Bale GA, Bright P, Sherwood Burge P. A double-blind placebo-controlled study of the effect of inhaled beclomethasone dipropionate for 2 years in patients with nonasthmatic chronic obstructive pulmonary disease. Clin Exp Allergy. 1999;29(Suppl 2):125-128.

18. Bourbeau J, Rouleau MY, Boucher S. Randomised controlled trial of inhaled corticosteroids in patients with chronic obstructive pulmonary disease. Thorax. 1998;53:477-482.

19. Calverley PM, Boonsawat W, Cseke Z, et al. Maintenance therapy with budesonide and formoterol in chronic obstructive pulmonary disease. Eur Respir J. 2003;22:912-919.

20. Pauwels RA, Lofdahl CG, Laitinen LA, et al. Long-term treatment with inhaled budesonide in persons with mild chronic obstructive pulmonary disease who continue smoking. European Respiratory Society Study on Chronic Obstructive Pulmonary Disease. N Engl J Med. 1999;340:1948-1953.

21. Renkema TE, Schouten JP, Koeter GH, Postma DS. Effects of long-term treatment with corticosteroids in COPD. Chest. 1996;109:1156-1162.

22. Szafranski W, Cukier A, Ramirez A, et al. Efficacy and safety of budesonide/formoterol in the management of chronic obstructive pulmonary disease. Eur Respir J. 2003;21:74-81.

23. Vestbo J, Sorensen $T$, Lange $P$, et al. Long-term effect of inhaled budesonide in mild and moderate chronic obstructive pulmonary disease: a randomised controlled trial. Lancet. 1999;353:1819-1823.

24. Albers M, Schermer T, van den Boom G, et al. Efficacy of inhaled steroids in undiagnosed subjects at high risk for COPD: results of the detection, intervention, and monitoring of COPD and asthma program. Chest. 2004;126:1815-1824.

25. Burge PS, Calverley PM, Jones PW, et al. Randomised, double blind, placebo controlled study of fluticasone propionate in patients with moderate to severe chronic obstructive pulmonary disease: the ISOLDE trial. BMJ. 2000;320:1297-1303.

26. Calverley P, Pauwels R, Vestbo J, et al. Combined salmeterol and fluticasone in the treatment of chronic obstructive pulmonary disease: a randomised controlled trial. Lancet. 2003;361:449-456.

27. Paggiaro PL, Dahle R, Bakran I, et al. Multicentre randomised placebo-controlled trial of inhaled fluticasone propionate in patients with chronic obstructive pulmonary disease. International COPD Study Group. Lancet. 1998;351:773-780.

28. van Grunsven P, Schermer T, Akkermans R, et al. Short- and longterm efficacy of fluticasone propionate in subjects with early signs and symptoms of chronic obstructive pulmonary disease. Results of the DIMCA study. Respir Med. 2003;97:1303-1312.

29. Effect of inhaled triamcinolone on the decline in pulmonary function in chronic obstructive pulmonary disease. N Engl J Med. 2000;343:1902-1909.

30. Jones A, Fay JK, Burr M, et al. Inhaled corticosteroid effects on bone metabolism in asthma and mild chronic obstructive pulmonary disease. Cochrane Database Syst Rev. 2002:CD003537.
31. Hubbard RB, Smith CJ, Smeeth L, Harrison TW, Tattersfield AE. Inhaled corticosteroids and hip fracture: a population-based casecontrol study. Am J Respir Crit Care Med. 2002;166:1563-1566.

32. Israel E, Banerjee TR, Fitzmaurice GM, et al. Effects of inhaled glucocorticoids on bone density in premenopausal women. N Engl J Med. 2001;345:941-947.

33. Johnell O, Pauwels R, Lofdahl CG, et al. Bone mineral density in patients with chronic obstructive pulmonary disease treated with budesonide Turbuhaler. Eur Respir J. 2002;19:1058-1063.

34. Lee TA, Weiss KB. Fracture risk associated with inhaled corticosteroid use in chronic obstructive pulmonary disease. Am J Respir Crit Care Med. 2004;169:855-859.

35. Cumming RG, Mitchell $P$, Leeder SR. Use of inhaled corticosteroids and the risk of cataracts. N Engl J Med. 1997;337:8-14.

36. Garbe E, Suissa S, LeLorier J. Association of inhaled corticosteroid use with cataract extraction in elderly patients. JAMA. 1998;280:539-543.

37. Jick SS, Vasilakis-Scaramozza C, Maier WC. The risk of cataract among users of inhaled steroids. Epidemiology. 2001;12:229-234.

38. Smeeth L, Boulis M, Hubbard R, Fletcher AE. A population based case-control study of cataract and inhaled corticosteroids. Br J Ophthalmol. 2003;87:1247-1251.

39. Garbe E, LeLorier J, Boivin JF, Suissa S. Inhaled and nasal glucocorticoids and the risks of ocular hypertension or open-angle glaucoma. JAMA. 1997;277:722-727.

40. Mitchell P, Cumming RG, Mackey DA. Inhaled corticosteroids, family history, and risk of glaucoma. Ophthalmology. 1999;106:2301-2306.

41. American Thoracic Society. Standards for the diagnosis \& management of patients with COPD. 2005. Available at: http://www.thoracic.org/copd. Accessed: September 22, 2005.

42. Hogger P. Dose response and therapeutic index of inhaled corticosteroids in asthma. Curr Opin Pulm Med. 2003;9:1-8.

43. Kelly HW. Pharmaceutical characteristics that influence the clinical efficacy of inhaled corticosteroids. Ann Allergy Asthma Immunol. 2003;91:326-334; quiz 334-325, 404.

44. Limaye SR, Pillai S, Tina LU. Relationship of steroid dose to degree of posterior subcapsular cataracts in nephrotic syndrome. Ann Ophthalmol. 1988;20:225-227.

45. Skalka HW, Prchal JT. Effect of corticosteroids on cataract formation. Arch Ophthalmol. 1980;98:1773-1777.

46. Seemungal TA, Donaldson GC, Paul EA, et al. Effect of exacerbation on quality of life in patients with chronic obstructive pulmonary disease. Am J Respir Crit Care Med. 1998;157:1418-1422.

47. Spencer S, Calverley PM, Burge PS, Jones PW. Impact of preventing exacerbations on deterioration of health status in COPD. Eur Respir J. 2004;23:698-702.

48. Fan VS, Bryson CL, Curtis JR, et al. Inhaled corticosteroids in chronic obstructive pulmonary disease and risk of death and hospitalization: time-dependent analysis. Am J Respir Crit Care Med. 2003; 168:1488-1494.

49. van der Valk P, Monninkhof E, van der Palen J, Zielhuis G, van Herwaarden C. Effect of discontinuation of inhaled corticosteroids in patients with chronic obstructive pulmonary disease: the COPE study. Am J Respir Crit Care Med. 2002;166:1358-1363.

50. Sin DD, Man SF. Inhaled corticosteroids and survival in chronic obstructive pulmonary disease: does the dose matter? Eur Respir J. 2003;21:260-266.

51. Sin DD, Tu JV. Inhaled corticosteroids and the risk of mortality and readmission in elderly patients with chronic obstructive pulmonary disease. Am J Respir Crit Care Med. 2001;164:580-584.

52. Sin DD, Tu JV. Inhaled corticosteroid therapy reduces the risk of rehospitalization and all-cause mortality in elderly asthmatics. Eur Respir J. 2001;17:380-385.

53. Suissa S. Effectiveness of inhaled corticosteroids in chronic obstructive pulmonary disease: immortal time bias in observational studies. Am J Respir Crit Care Med. 2003;168:49-53.

54. Vestbo J. The TORCH (towards a revolution in COPD health) survival study protocol. Eur Respir J. 2004;24:206-210. 